\title{
Introduction to the Special Issue on Systemic Approaches to Mass Trauma
}

\section{Alyssa Banford Witting ${ }^{1}$}

Published online: 27 July 2018

(c) Springer Science+Business Media, LLC, part of Springer Nature 2018
Large scale traumatic events or processes, sometimes referred to as mass trauma (Pfefferbaum et al. 2008) or complex human emergencies (when spurred by or interacting with sociopolitical unrest) (Pugh 1995; Burkle and Hayden 2001), take various forms and have myriad effects. Mass trauma may be defined broadly to include natural disasters, technological disasters, wars, environmental degradation, organized violence, and systematic institutional racism and other forms of structural inequity. The reach and influence of these events is clearly linked to individual and relational suffering, as will be demonstrated, in part, by the studies in this issue. In a current global environment of tension, fear, climate change, economic volatility and war, it is likely that we will experience continued incidences of mass trauma (Mayhorn and McLaughlin, in press).

The field of marriage and family therapy as well as sister mental health disciplines have taken on the task of developing and implementing empirically supported treatments for individuals, couples and families affected by such events. For detailed information on the effects of war and violence on families as well as empirically supported, systemically oriented treatments for forcibly displaced populations affected by war, torture and organized violence, we refer the reader to the Journal of Marital and Family Therapy (JMFT) special section on Mass Trauma edited by Wieling and Mittal (2008), and the more recent special section in JMFT on Family Interventions for Populations Exposed to Traumatic Stress Related to War and Violence edited by Wieling (2017). The current special issue grapples with several research questions to further texture our understanding of the nature of traumatic stress itself and subsequently the mass-scale events which may cause it or exacerbate it.

Alyssa Banford Witting

alyssa_banfordwitting@byu.edu

1 Brigham Young University, School of Family Life, Provo, UT, USA
The nature of traumatic stress from a diagnostic standpoint has been defined and defined again over generations of mental health care provision in the US and internationally (APA 2000, 2013; World Health Organization (WHO) 2018). Typically, diagnostic underpinnings for post-traumatic stress disorder are cast to capture an experience centered in an individual as opposed to a relational system and are representative of a pathological experience as opposed to a systemic pattern of interacting in the world and relationships (Wieling and Mittal 2008). Such a definition does not adequately account for the complicated nature of traumatic stress which is rooted in ecological origins and reverberates systemically through whole families (Wieling 2017). Each manuscript in this special issue hearkens to this topic by including a discussion of how traumatic stress manifests itself in relationships with others which is central to our understanding of trauma as a systemic matter in the field of Marriage and Family Therapy.

The beginning manuscript entitled Much more than PTSD: Mother's narratives of the impact of trauma on child survivors and their families written by Stephen Coulter and Suzanne Mooney elucidates the family-level experience of a traumatic event experienced by an individual within a family. Coulter and Mooney conducted qualitative interviews with 10 mothers of children exposed to various traumatic events. They asked the mothers to simply tell the story of how the traumatic events affected them and their families. They identified 729 relevant content items speaking to this prompt and accompanying follow-up questions and showed that the largest proportion of the content was centered in family and relational distress. Their discussion, while rooted in an experience of trauma of one family member (as opposed to a mass trauma), in this issue serves as a lead-in to a broader discussion of what the effects of mass trauma events may be in relational systems. The authors argue for a broadening of our understanding of the nature of the diagnostics of PTSD to account for relational complexities which accompany traumatic stress. 
The next manuscript carries forward the discussion of the complexity of trauma events as they influence family relationships and processes. It is entitled Mother-child relationships following a disaster: The experiences of Turkish mothers living in a container city after the 2011 Van earthquake. Cigdem Yumbul, Elizabeth Wieling, and Hilal Celik report on interviews carried out with mothers affected by the earthquake and subsequent displacement. The authors discovered and detailed a process of how: the traumatic stress related to events of the earthquake and subsequent displacement led to maternal difficulty in emotion regulation which in turn altered parenting behaviors which finally influenced the mother's perception of her relationship with her child. This manuscript adds to our understanding of how traumatic stress is ecological in its movement through system levels and may reverberate through geographical region, national and local political response systems through the individual emotion regulation system and out through the family system.

The next manuscript continues the examination of relationships in the wake of mass-trauma. Rebecca Lucero, Adam Jones and Jacob C. Hunsaker contributed the manuscript entitled Using internal family systems theory in the treatment of combat veterans with post-traumatic stress disorder and their families. This paper is a discussion piece highlighting the lack of systemic, relationally oriented treatment for combat-veterans facing trauma symptoms with incredibly high frequency. They explore the use of IFS as an accessible and useful way to infuse trauma-treatment with less individual focus for combat veterans. The authors recast the tenets of IFS in light of working with combat trauma and argue for its increased use with veterans.

Joe Grady, myself, Angela Kim and Sean Davis wrote the following manuscript dealing with combat trauma and relationships entitled Differences in unit cohesion and combatrelated mental health problems based on attachment style in US military veterans. In a sample of combat-exposed veterans, we hypothesized that attachment style with one's partner would associate with mean differences in remembered cohesion with one's military unit and measures of anxiety, depression and trauma symptoms. Results showed that insecure attachment to a partner related to greater distress in mental health symptoms post military service. However, military unit cohesion was high across attachment styles and didn't differ significantly. This study highlights the potential protective nature of secure partner relationships in the wake of involvement in mass trauma such as war and raises further questions about the nature of relationships and identities born of and organized around the trauma such as one's military unit.

The notion of identity and contextual factors as inextricably linked to the experience of traumatic stress is carried forward to be the focus of the next three issue. One article entitled Posttraumatic cognitions and depressive symptoms in war and disaster affected widows in Sri Lanka: The role of community support was written by Jessica Lambert, myself, Shayne Anderson, Lakmal Ponnamperuma and Thulitha Wickrama. This paper was written with data collected from a sample of Sri Lankan widows living in an are of the county that was deeply affected by the 25 -year civil war which ended in 2009 as well as the 2004 tsunami which struck southeastern Asia. We looked particularly at how contextual problems resulting from the war and tsunami-related losses associated with community support and problematic posttraumatic cognitions as intermediaries which in turn associated with PTSD and depression symptoms. Our findings ultimately suggested that context problems (e.g. social and infrastructure changes) resulting from the war related to lower levels of community support and higher levels of negative posttraumatic cognitions. Also, greater levels of community support associated with less mental health distress. This paper is an illustration of the complex influence of protracted stressors on the context in which one lives which may in turn decrease resources and result in greater distress years after events are "over." Additionally, we focus on the importance of community support (a systemic and relational factor) as a potential mitigating influence in mental health distress in the context of trauma.

Next, the article entitled First-Generation Iranian Refugees' Acculturation in the United States: A Focus on Resilience examines context again as it describes the lived experience of 10 Iranian refugees' in the United States. It was written by Tania Hormozi, Marianne Miller and myself. The focus of the refugees' experience in this transcendental phenomenology was to understand key themes connecting the refugees lives, post migration. We found that participants' relationship with God, seeking for greater opportunities and political freedom was a key factor for many in their decision to migrate from Iran. Participants discussed several specific context challenges they faced in the process. These challenges were examined through a framework of resilience and the discussion around them included the strengths refugees employed to manage their challenges including, "flexibility, adaptability, persistence, staying strong, religious conviction, maintaining good connections, education, and language ability."

The final article in this issue conceptualizes institutional racism toward Black Americans and African Americans as a systematic form of mass trauma evidenced by violence toward Black Americans. The sixth article is entitled Mass trauma in the African American community: Using multiculturalism to build resilient systems. It was written by Bryan Range, Dumayi Gutierrez, Casey Gamboni, Nathan Hough, and Armeda Wojciak. This article makes conceptual bridges to link various features of trauma to the experience of longstanding institutional racism in the US and introduces a 
multiphase model of therapy to address this issue with Black American clients using the shooting of Philando Castile as a case example. The authors argue that "MFT's are trained to be systemic thinkers and to see individuals and families in the context of the larger systems in which they exist." They include several suggestions for therapists to more consciously include racism and cultural factors in their assessment and approach to trauma.

\section{References}

American Psychiatric Association. (2000). Diagnostic and statistical manual of mental disorders (4th ed.). Washington, DC: Author. (Text Revision)

American Psychiatric Association. (2013). Diagnostic and statistical manual of mental disorders (5th ed.). Washington, DC: Author.

Burkle, F. M., \& Hayden, R. (2001). The concept of assisted management of large-scale disaster by horizontal organizations. Prehospital and Disaster Medicine, 16(3), 128-137. https://doi. org/10.1017/S1049023X00025875.

Mayhorn, C. B., \& McLaughlin, A. C. (in press). Warning the world of extreme events: A global perspective on risk communication for natural and technological disaster. Safety Science. Retrieved from https://s3.amazonaws.com/academia.edu.documents/46509846/ Warning_the_world_of_extreme_events_A_gl20160615-21111 -1n6mwhx.pdf?AWSAccessKeyId=AKIAIWOWYYGZ2Y5 3UL3A\&Expires $=1522952811 \&$ Signature $=c b 3$ Y3LlarXw2W8Q gjk\%2BtqIMpvyg\%3D\&response-content-disposition=inlin e\%3B\%20filename\%3DWarning_the_world_of_extreme_event s_A_gl.pdf.

Pfefferbaum, B. J., Reissman, D. B., Pfefferbaum, R. L., Klomp, R. W., \& Gurwitch, R. H. (2008). Building resilience to mass trauma events. In L. S. Doll, S. E. Bonzo, D. A. Sleet \& J. A. Mercy (Eds.), Handbook of injury and violence prevention. Boston: Springer.

Pugh, M. (1995). Peacebuilding as developmentalism. Contemporary Security Policy, 16(3), 320-346. https://doi.org/10.1080/13523 269508404120.

Wieling, E. (2017). Family interventions for populations exposed to traumatic stress related to war and violence. Journal of Marital and Family Therapy. https://doi.org/10.1111/jmft.12297.

Wieling, E., \& Mittal, M. (2008). JMFT special section on mass trauma. Journal of Marital and Family Therapy, 34(2), 127-131. https://doi.org/10.1111/j.1752-0606.2008.00059.x.

World Health Organization. (2018). Classifications. Retrieved from http://www.who.int/classifications/icd/revision/en/. 